\title{
Effect of Recitation of Tawassul Prayer on Anxiety and Physiological Parameters of Patients with Myocardial Infarction Admitted to Coronary Care Unit: A Randomized Clinical Trial
}

\author{
Rahmat Shafiepour Sadati1, Nayyereh Raiesdana2,, Mohammad Reza Asgari², Majid Mirmohammadkhani3, \\ Mehrdad Zahmatkesh ${ }^{4}$ and Mehrdad Saravi ${ }^{5}$
}

${ }^{1}$ Student Research Committee, Semnan University of Medical Sciences, Semnan, Iran

${ }^{2}$ Nursing Care Research Center, Semnan University of Medical Sciences, Semnan, Iran

3Social Determinants of Health Research Center, Semnan University of Medical Sciences, Semnan, Iran

${ }^{4}$ Nursing and Midwifery Faculty, Semnan University of Medical Sciences, Semnan, Iran

${ }^{5}$ Department of Cardiology, Babol University of Medical Sciences, Mazandaran, Iran

* Corresponding author: Nayyereh Raiesdana, Nursing and Midwifery College, Semnan University of Medical Sciences, 5 Kilometer of Damghan Road, Semnan, Iran. Tel: +9802333654191; Email: nr_dana@semums.ac.ir

Received 2021 February 13; Revised 2021 May 17; Accepted 2021 June 17.

\begin{abstract}
Background: Anxiety following acute myocardial infarction is a particularly important issue. Prayer is one of the basic human needs that is related to mental health.

Objectives: In this regard, this study aimed to determine the effect of recitation of Tawassul prayer on anxiety and physiological parameters of patients with myocardial infarction.

Methods: This clinical trial was performed on 80 patients for 6 months from August 2017 to March 2018. They were selected by the targeted sampling method and randomly assigned to two groups with gender and age block randomization. The subjects were asked to complete the anxiety subscale of the Hospital Anxiety and Depression Scale. Physiologic parameters were measured and participants in the intervention group listened to the recitation of the Tawassul Prayer with headphones.

Results: In the intervention group, the mean of anxiety scores before and after intervention were $11.17 \pm 3.06$ and $5.81 \pm 3.16$, respectively, which had a significant difference $(\mathrm{P}<0.001)$. There was a significant difference between the two groups in terms of the mean scores of anxiety before and after intervention $(\mathrm{P}<0.001)$ and the respiratory rate before and after intervention $(\mathrm{P}=0.025)$.

Conclusion: Prayer affected the level of anxiety and respiratory rate. This prayer is useful for reducing anxiety and improving the respiratory rate in patients with myocardial infarction.

Keywords: Anxiety, Coronary care unit, Myocardial infarction, Prayer, Tawassul prayer
\end{abstract}

\section{Background}

Myocardial infarction (MI) is a Life-threatening and stressful event that can affect all the physical, spiritual, and psychosocial aspects of human life (1). A review of related literature indicated that the anxiety level of patients with cardiovascular diseases is higher than that of healthy adults and is about $17.26 \%$ following MI (2). Since emotional distress has a prognostic value in these patients, screening and control of anxiety are necessary (3).

The cardiovascular system is highly sensitive to different emotions, such as stress, anxiety, fear, anger, and happiness; for this reason, these emotions can immediately cause changes in the heart rate and blood pressure (4). Anxiety activates the sympathetic nervous system and the hypothalamic-pituitaryadrenal axis which has destructive effects and complications, increases the time of hospitalization, and leads to poorer tableoutcomes (3). Therefore, modulating and reducing anxiety in these patients should be an important goal (5). It should be noted that management of anxiety and achievement of a positive psychological state can cause superior cardiac outcomes (6).
Results of a qualitative study showed that the lifethreatening and critical nature of MI strengthens the spiritual aspect of MI patients which helps them to recover. People with anxiety, often turn to religion for the management of their anxiety. Spirituality and religious practices are major sources of adaptation to critical conditions, such as acute MI (1).

From centuries ago, many complementary approaches, such as prayer, have been used in the domain of nursing as they can easily be employed for the reduction of anxiety in patients with cardiovascular diseases (7). Prayer has been a healing practice from an ancient time and in holistic nursing practice, nurses must be familiar with prayer and its potential uses in different situations (8). Prayer has a positive effect on decreasing the severity of the illness of patients in the intensive care unit (ICU) (9). Praying can also create hopefulness and internal serenity and lead to a meaningful life. The relationship with God for faithful people is similar to a relationship with an intimate friend. By having recourse to God, they can control the unwanted effects of unpleasant situations (10).

One of the specific prayers of Muslims is called Tawassul prayer. According to a classification by 
Perez et al. (2004), Tawassul prayer (resorting to Imams) is a supplication or appeal form of prayer that focuses on asking for the intervention of God or the occurrence of certain events in life for oneself or others (11). This Prayer requires the presence of the heart and preparation for praying to God by resorting to the Fourteen Infallibles (Prophet Muhammad, Prophet Fatimah, and Imam Ali and the 11 Imams after him). Through the Infallibles, humans are drawn to God and can make their requests easier (Mafatih al-Janan). In the traditions of the Prophet Muhammad and the Innocent Imams, the necessity of resorting to divine authority when praying is emphasized (12).

In several studies, the effect of Tawassul prayer has been identified on the mental health of students (13), the mental health of patients undergoing hemodialysis (14), quality of life of cancer patients (15), the anxiety of mothers of children with cancer (16), and anxiety of new nursing students (17).

Since Tawassul prayer is one of the prayers that is answered fast by God, it seems that in emergencies where one's health is compromised, like MI, such prayers are more effective than the other types of prayer and may be effective in reducing anxiety (13).

\section{Objectives}

Prayer has a special place in the culture and context of our country. Given the necessity of comprehensive holistic patient care, a few studies have been conducted on the effects of Tawassul prayer in acute clinical settings. Based on the observations of researchers about the recitation of this prayer by patients and their families in the ICUs, this study aimed to investigate the effect of Tawassul prayer on anxiety and physiological parameters of patients with MI based on a scientific method.

\section{Methods}

\subsection{Study design}

The present clinical trial was performed on patients with MI that were randomly assigned to either an intervention or a control group. According to the study conducted by Najafi et al. (18) on the effect of simultaneous aromatherapy and Quran recitation on the anxiety level of patients with MI, the sample size was estimated at 80 patients (40 patients in each group). Maximum type I and type II errors were considered $5 \%$ and $20 \%$, respectively. Participants were selected from the Coronary Care Unit (CCU) at Shahid Rouhani Hospital with eight beds in Babol, Iran.

For the random assignment, first, four subgroups (stratum) were assigned: 1) 40-60 years old females, 2) 40-60 years old males, 3) 61-80 years old females, and 4) 61-80 years old males. Next, the randomized random list for each stratum (4 predefined lists) was used to assign each subject to either the intervention (A) or control (B) group. To create the desired list of six possible blocks, quadrants were assigned to each numerical block (from I to VI). According to the random number table, numbers 1-6 correspond to the above-mentioned blocks, and numbers 7-9 and 0 are not counted. It must be noted that the random numbers were generated with Create a blocked randomization list. [Online] Afterward, the assignment list (from left to right) was determined for each stratum.

Sampling was performed in six months from August 2017 to March 2018. The inclusion criteria were: 1) admission to CCU for the first time, 2) definitive diagnosis of heart attack based on the diagnosis of a specialist, 3) willingness to participate in the study, 4) being Muslim and Shia, 5) age range of 40-80 years old, 6) ability to read and write.

On the other hand, the exclusion criteria were: 1) any known hearing impairment and pain during the research, 2) history of known anxiety and psychiatric disorders, 3) cardiopulmonary resuscitation on arrival at the emergency and during the study, 4) use of tranquilizer drugs during the study without the prescription of the doctor, 5) heart dysrhythmia, ventricular fibrillation, ventricular tachycardia, cardiogenic shock, and significant changes in the medical or psychiatric condition during the study.

Data were collected using a three-part questionnaire, including 1) a demographic questionnaire asking about the gender, age, marital status, literacy level, and occupation, 2) Anxiety Inventory subscale of Hospital and Depression Scale (HADS), and 3) a sheet for recording physiologic parameters.

The Anxiety Inventory subscale of HADS is a seven-item self-report tool designed to determine the presence and severity of anxiety symptoms in patients over the past week. The time required for its completion is less than $5 \mathrm{~min}$ and its target population is people 16 years old and above. It should be noted that each test component is scored based on a scale of $0-3$. Therefore, the scores on the Anxiety Inventory subscale are within the range of $0-21$. Scores within the ranges of $0-7,8-10,11-14$, and 1521 are considered normal, mild, moderate, and severe anxiety. Each one of the subscales can be used separately (19). The reliability and validity of the Persian version of the HADS were proved in a study performed by Hossein Kaviani et al. in 2010 (20). Cronbach's alpha coefficient of this questionnaire in a sample of Iranian patients for anxiety subscale was 0.78 and it is well able to differentiate patients with anxiety from non-anxiety patients (21). Moreover, the reliability of this scale in this research was 0.72 by Cronbach's alpha. 


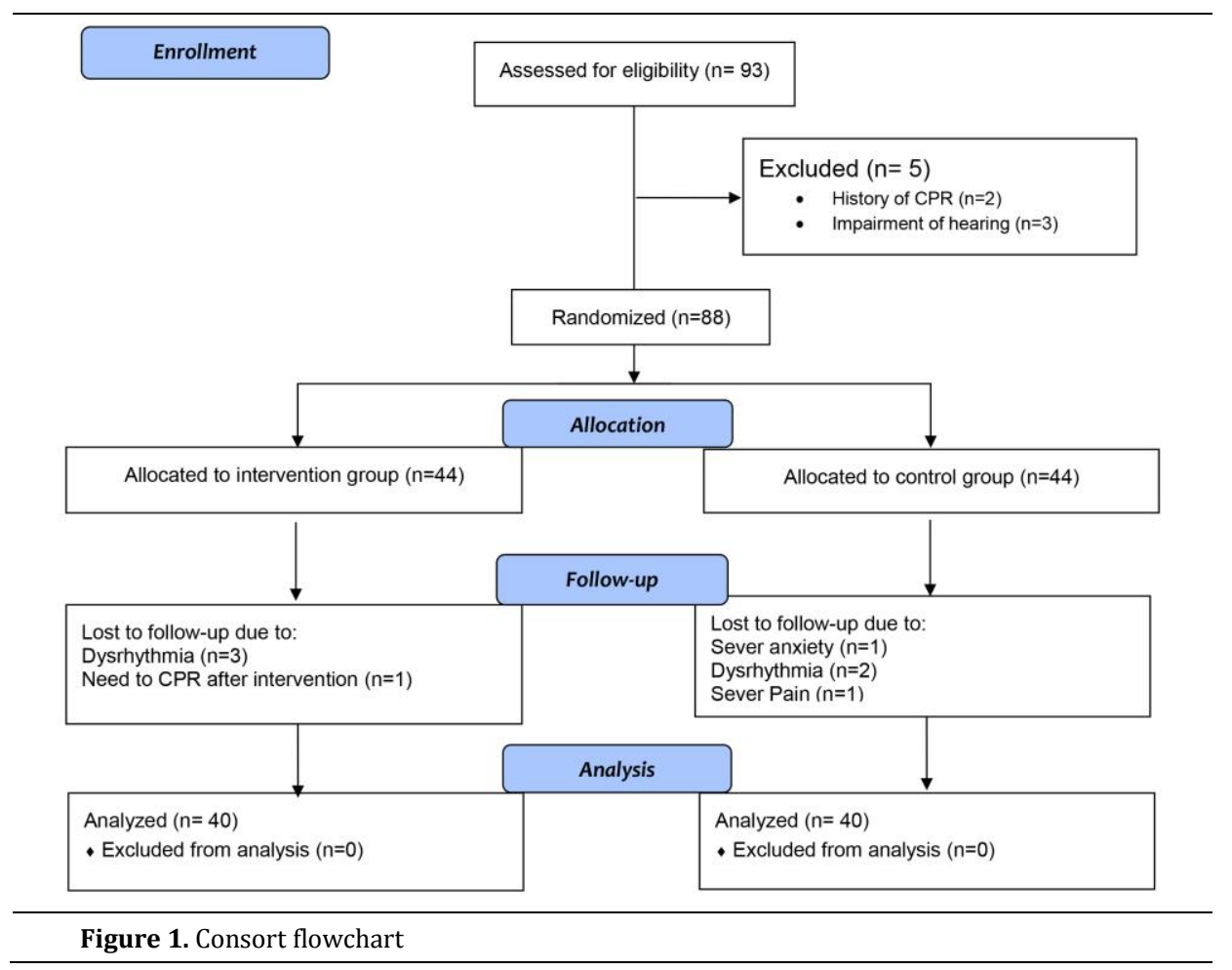

At first, the demographic and anxiety subscale of HADS was self-completed at baseline $(6 \mathrm{~h}$ after arrival to CCU). Moreover, the blood pressure, respiratory rate, and heart rate of all the participants of intervention and control groups were measured for the first time by Patient Care Monitor Alborz B5 (Alborz, Iran). Next, the participants in the intervention group listened to the recitation of Tawassul prayer by Farahmand Master, a well-known reciter, using an MP3 player with headphones for 14 min and $30 \mathrm{sec}$. The Shiites in general and the Iranians use this prayer, in particular, to fulfill their needs by resorting to imams. In addition, immediately after completion of Tawassul prayer, the Anxiety subscale of HADS was completed by participants and their physiologic parameters were measured for the second time.

Participants in the control group rested in beds during the intervention. Afterward, they completed the anxiety subscale of HADS and their physiologic parameters were measured for the second time.

\subsection{Ethical considerations}

The study was performed after obtaining approval from the Ethics Committee of Semnan University of Medical Sciences, Semnan, Iran (Code: IR.SEMUMS. REC1396.88) and registering the trial in the Iranian Registry of Clinical Trials (ID: IRCT20170718 18550N5). Moreover, informed written consent was obtained from all participants before their enrollment in the trial.

\subsection{Statistical Analysis}

The data were analyzed in SPSS software (version
16) using descriptive and inferential statistical tests. The results of the normality test showed that except for blood pressure, other numerical variables did not show normal distribution. Hence, the paired t-test and Wilcoxon test were used to compare intragroup differences before and after the intervention, and student's t-test and Mann Whitney U test were used to compare the intergroup group differences. It should be mentioned that a p-value of less than 0.05 was considered statically significant.

\section{Results}

In total, 80 patients were included in the study, all of whom 80 agreed $(100 \%)$ to participate in the study. These patients with a definite diagnosis of MI were randomly allocated to either the intervention $(n=40)$ or control groups $(n=40)$. Table 1 presents the demographic characteristics of the participants at baseline.

In this research, the subjects in each group were arranged in blocks with regard to gender and age (40-60 and 61-80). The only difference between the groups was that participants in the intervention group were significantly younger than those in the control group ( 50.2 vs. 56.4 years, $\mathrm{P}=0.046$ ).

Table 2 summarizes the mean and standard deviation values of Anxiety scores at baseline and follow-up stages. At baseline, the mean anxiety scores in the intervention group were significantly higher than those in the control group $(11.17 \pm 3.06$ vs. $9.48 \pm 3.83, \mathrm{P}=0.014)$. After the intervention, the mean Anxiety score of the intervention group decreased from 11.17 to 5.81 , nearly a six-point decrease, 


\begin{tabular}{|c|c|c|c|}
\hline & Total & Intervention & Control \\
\hline Gender (male) N (\%) & $80(100)$ & $40(50)$ & $40(50)$ \\
\hline \multicolumn{4}{|l|}{ Age } \\
\hline $40-60$ & $40(50)$ & $20(25)$ & $20(25)$ \\
\hline $61-80$ & $40(50)$ & $20(25)$ & $20(25)$ \\
\hline \multicolumn{4}{|l|}{ Literacy level } \\
\hline Primary school & $44(55)$ & $19(47.5)$ & $25(62.5)$ \\
\hline Secondary school & $20(25)$ & $9(22.5)$ & $11(27.5)$ \\
\hline Academic education & $16(20)$ & $12(30)$ & $4(10)$ \\
\hline \multicolumn{4}{|l|}{ Occupation } \\
\hline Housekeeper & $33(41.25)$ & $18(45)$ & $15(37.5)$ \\
\hline Worker(laborer) & $26(32.5)$ & $12(30)$ & $14(35)$ \\
\hline Employee & $11(13.75)$ & $5(12.5)$ & $6(15)$ \\
\hline Retired & $10(12.5)$ & $5(12.5)$ & $5(12.5)$ \\
\hline \multicolumn{4}{|l|}{ Marital status } \\
\hline Single & $2(2.5)$ & $1(2.5)$ & $1(2.5)$ \\
\hline Married & $72(90)$ & 37 (92.5) & 35 (87.5) \\
\hline Divorced & $6(7.5)$ & $2(5)$ & $4(10)$ \\
\hline
\end{tabular}

\begin{tabular}{|c|c|c|c|c|}
\hline & $\begin{array}{c}\text { Intervention } \\
\text { Mean } \pm \text { SD }\end{array}$ & $\begin{array}{c}\text { Control } \\
\text { Mean } \pm \text { SD }\end{array}$ & $\begin{array}{l}\text { Difference } \\
\text { Mean } \pm \text { SD }\end{array}$ & Intergroup p-value \\
\hline Baseline & $11.17 \pm 3.06$ & $9.48 \pm 3.83$ & $5.18 \pm 4.33$ & $0.014^{* *}$ \\
\hline Post-intervention & $5.81 \pm 3.16$ & $9.21 \pm 4.02$ & $0.27 \pm 1.01$ & $<0.001^{* *}$ \\
\hline \multirow{2}{*}{\multicolumn{5}{|c|}{$\begin{array}{l}\text { p-value in each group } \\
{ }^{*} \text { Paired t-test }{ }^{* *} \text { Student's t-test }\end{array}$}} \\
\hline & & & & \\
\hline \multicolumn{2}{|l|}{ Physiologic parameters } & $\begin{array}{l}\text { Intervention } \\
\text { Mean } \pm \text { SD }\end{array}$ & $\begin{array}{c}\text { Control } \\
\text { Mean } \pm \text { SD }\end{array}$ & Intergroup p-value \\
\hline \multirow{4}{*}{ Systolic blood pressure } & Baseline & $121.47 \pm 19.15$ & $120.66 \pm 21.64$ & \multirow{4}{*}{$0.978^{* *}$} \\
\hline & Post-intervention & $119.12 \pm 17.53$ & $118.37 \pm 19.40$ & \\
\hline & Mean Difference \pm SD & $2.35 \pm 8.58$ & $2.29 \pm 10.11$ & \\
\hline & p-value in each group & $0.091^{*}$ & $0.160^{*}$ & \\
\hline \multirow{4}{*}{ Diastolic blood pressure } & Baseline & $77.26 \pm 11.69$ & $76.12 \pm 13.28$ & \multirow{4}{*}{$0.573^{* *}$} \\
\hline & Post-intervention & $73.80 \pm 10.79$ & $75.09 \pm 12.21$ & \\
\hline & Mean Difference \pm SD & $3.46 \pm 7.63$ & $1.02 \pm 9.65$ & \\
\hline & Intragroup p-value & $0.002^{*}$ & $0.272^{*}$ & \\
\hline \multirow{4}{*}{ Pulse rate } & Baseline & $80.27 \pm 14.21$ & $82.62 \pm 16.58$ & \multirow{4}{*}{$0.208^{* *}$} \\
\hline & Post-intervention & $77.4 \pm 11.41$ & $81.25 \pm 14.15$ & \\
\hline & Mean Difference \pm SD & $2.87 \pm 7.83$ & $1.37 \pm 6.41$ & \\
\hline & Intragroup p-value & $0.017^{*}$ & $0.408^{*}$ & \\
\hline \multirow{4}{*}{ Respiratory rate } & Baseline & $17.82 \pm 4.38$ & $18.25 \pm 3.92$ & \multirow{4}{*}{$0.025^{* *}$} \\
\hline & Post-intervention & $16.25 \pm 3.43$ & $17.62 \pm 3.86$ & \\
\hline & Mean Difference $\pm S D$ & $1.57 \pm 2.19$ & $0.62 \pm 1.62$ & \\
\hline & Intragroup p-value & $<0.001^{*}$ & $0.026^{*}$ & \\
\hline
\end{tabular}

*Paired t-test $\quad$ **Student's t-test

whereas that of the control group underwent a very small change as it decreased from 9.48 to 9.21. Intragroup mean values were compared using the paired t-test and intergroup mean values were compared using the independent t-test. Results of the mean and standard deviation of physiologic parameters at baseline and post-intervention stage are summarized in Table 3.

\section{Discussion}

Following the global neglect, from the mid-1980s until now, prayer has gained central importance in understanding the effect of religion and spirituality on human health (22). Religion and religious practices are embedded in the Iranian culture. Hence, paying attention to spiritual needs during the illness and recovery period plays a crucial role, and healthcare workers must consider this aspect as well as other aspects of care in MI patients (1). To date, many research projects have supported the idea that different prayers have healing effects; nevertheless, based on our knowledge, this is the first study performed in clinical situations to assess the effects of listening to Tawassul prayer on anxiety and physiologic parameters of patients with MI.

Results of the present study showed that there was a significant difference between the mean scores of anxiety before and after the intervention in the intervention group $(\mathrm{P}<0.001)$. It was also found that there was a significant difference between the mean scores of anxiety before and after the intervention between the intervention and control groups 
$(\mathrm{P}<0.001)$. In other words, listening to Tawassul prayer was effective in decreasing the anxiety score of the intervention group. It is noteworthy that the difference between the mean scores of anxiety of the two groups was also significant.

This finding is consistent with those of a study that indicated listening to Tawassul prayer reduced anxiety in new students of Ahvaz Jundishapur University of Medical Sciences (17). Moreover, it is in line with the results of another study which showed that recitation of Tawassul prayer twice a week during one month was associated with a significant reduction in the anxiety of pregnant women (23).

The difference between the mean pulse rate of the subjects before and after the intervention was significant in the intervention group $(\mathrm{P}=0.026)$, while there was no significant difference between the mean pulse rate of the intervention and control groups. This finding is consistent with that of a study that indicated a significant difference between the mean pulse rates of subjects in the Holy Quran group before and after the intervention (24). Non-significant differences between the mean pulse rates of intervention and control groups can be due to the use of Propranolol to control heart rate in routine MI care. Majidi (2004) stated that before angiography, patients were admitted to ICUs and received propranolol in their medication regimen; hence, there was no significant difference between the mean heart rates of the two groups (25).

There was no significant difference between the mean values of systolic blood pressure before and after the intervention in each group and between the two groups. However, there was a significant difference between the mean diastolic blood pressure before and after the intervention in the intervention group $(\mathrm{P}=0.007)$, while there was no significant difference between the two groups in this regard.

To date, no study has been carried out on the effect of Tawassul prayer on patients, but in the study of Tayebi et al. (2014), listening to Quranic prayer significantly reduced systolic $(\mathrm{P}=0.000)$ and diastolic $(\mathrm{P}=0.001)$ blood pressure in the intervention group $(\mathrm{P}=0.000)(26)$. It seems that the reason for the lack of significant changes in blood pressure in patients is related to the usual use of $\beta$-adrenergic blocking agents, such as Propranolol in the treatment of MI patients (27).

Some researchers also referred to the effects of antihypertensive drugs on blood pressure measurement in their study (28). Another study was conducted on the effects of the sound of the Holy Quran on the anxiety and pain of patients undergoing spinal anesthesia for cesarean section. The results of the aforementioned study showed that the mean arterial blood pressure of the intervention group was significantly lower than that of the control group before, during, and after the surgery (29).

Findings of this study indicated that there was a significant difference between the mean respiratory rates of the intervention $(\mathrm{P}<0.001)$ and control $(\mathrm{P}=0.026)$ groups before and after the intervention. In addition, there was a significant difference between mean difference of respiratory rate of the two groups before and after the intervention $(\mathrm{P}=0.025)$. This finding is consistent with that of a research project conducted by Tayebi et al.(2014) in which the respiratory rate decreased in the intervention group after hearing to Holy Quran prayers (26). This is also consistent with the results of a study performed by Ildar Abadi et al. (2003) which showed a significant decrease in the respiratory rate of the intervention group after the intervention (30).

\section{Limitation}

One of the limitations of this study was the impossibility of investigating the existence of anxiety disorders and psychiatric disorders in the subjects.

\section{Conclusion}

Prayer is a spiritual activity that is often used by patients to facilitate health and promote well-being during illness. The scientific community recognizes prayer as a complementary therapy. Prayer has a very special place in the religion of Islam. Prayer has been introduced to relieve anxieties and worries and illuminate the human heart. The present research was the first study about the effects of Tawassul prayer on patients with MI. The findings indicated that Tawassul prayer can alleviate anxiety and respiratory rate of patients with a definite diagnosis of MI admitted to CCU.

\section{Footnotes}

Authors' Contributions: Rahmat Shafiepour Sadati: conceived the project, collected the data, and wrote the draft of the paper. Nayyereh Raiesdana: designed and supervised the project and edited final proof. Majid Mirmohammadkhani: participated in data analysis and interpretation. Mohammad Reza Asgari: designed the project, consulted its integrity, and wrote the draft. Mehrdad Saravi: supervised the integrity of the data collection. Mehrdad Zahmatkesh: wrote the draft of the paper and edited the final version.

Conflicts of Interest: There is no conflict of interest related to this study.

Funding: This study has been done with the financial support of Semnan University of Medical Sciences.

\section{References}

1. Momennasab M, Moattari M, Abbaszade A, Shamshiri B. Spirituality in survivors of myocardial infarction. Iran J Nurs Midwifery Res. 2012;17(5):343-51. [PubMed: 23853646].

2. Feng HP, Chien WC, Cheng WT, Chung $\mathrm{CH}$, Cheng SM, Tzeng 
WC. Risk of anxiety and depressive disorders in patients with myocardial infarction: a nationwide population-based cohort study. Medicine. 2016;95(34):e4464. doi: 10.1097/MD.0000 000000004464. [PubMed: 27559951].

3. Ulvik B, Bjelland I, Hanestad BR, Omenaas E, Wentzel-Larsen T, Nygård 0. Comparison of the short form 36 and the hospital anxiety and depression scale measuring emotional distress in patients admitted for elective coronary angiography. Heart Lung. 2008;37(4):286-95. doi: 10.1016/j.hrtlng.2007.08.001. [PubMed: 18620104].

4. Craven RF, Hirnle CJ, Jensen S. Fundamentals of nursing. Philadelphia: Lippincott Williams \& Wilkins; 2013.

5. Moser DK, Dracup K, Evangelista LS, Zambroski CH, Lennie TA, Chung ML, et al. Comparison of prevalence of symptoms of depression, anxiety, and hostility in elderly patients with heart failure, myocardial infarction, and a coronary artery bypass graft. Heart Lung. 2010;39(5):378-85. doi: 10.1016/j.hrtlng.2009.10.017. [PubMed: 20561849].

6. Huffman JC, Smith FA, Blais MA, Januzzi JL, Fricchione GL. Anxiety, independent of depressive symptoms, is associated with in-hospital cardiac complications after acute myocardial infarction. J Psychosom Res. 2008;65(6):557-63. doi: 10.1016/j.jpsychores.2008.08.001. [PubMed: 19027445].

7. Kreitzer MJ, Snyder M. Healing the heart: integrating complementary therapies and healing practices into the care of cardiovascular patients. Prog Cardiovasc Nurs. 2002;17 (1):73-80. doi: 10.1111/j.0889-7204.2002.00626.x. [PubMed: 11986540].

8. Ameling A. Prayer: an ancient healing practice becomes new again. Holist Nurs Pract. 2000;14(3):40-8. doi: 10.1097/ 00004650-200004000-00008. [PubMed: 12119627].

9. Taghizade Karati K, Asadzandi M ,Tadrisi SD, Ebadi A. Effect of prayer on severity of patients illness in intensive care units. Iran J Crit Care Nurs. 2011;4(1):1-6.

10. Rahimi A, Anoosheh M, Ahmadi F, Foroughan M. Exploring spirituality in Iranian healthy elderly people: a qualitative content analysis. Iran J Nurs Midwifery Res. 2013;18(2):16370. [PubMed: 23983748].

11. Perez JE, Rex Smith A, Norris RL, Canenguez KM, Tracey EF, Decristofaro SB. Types of prayer and depressive symptoms among cancer patients: the mediating role of rumination and social support. J Behav Med. 2011;34(6):519-30. doi: 10.1007/s10865-011-9333-9. [PubMed: 21487725].

12. Recourse prayer. Islam Quest Net. Available at: URL: http://www.islamquest.net/fa/archive/question/1316; 2014.

13. Farmahini Farahani M, Ghorbani M. Effect of tavassol prayer on mental health of second year nursing students of school of nursing. Complement Med J. 2012;2(2):135-47.

14. Sharif NS, Hojjati H, Nazari R, Qorbani M, Akhoondzade G. The effect of prayer on mental health of hemodialysis patients. Iran J Crit Care Nurs. 2012;5(1):29-34.

15. Bahrami M, Balouchestani E, Amini A, Eghbali M. Assessing the effect of two praying methods on the life quality of patients suffering from cancer hospitalized at Seyedo Shohada medical center of Isfahan University of Medical Sciences. Iran J Nurs Midwifery Res. 2010;15(Suppl 1):296-301. [PubMed: 22069403].
16. Dehghani K, Zare Rahimabadi A, Pourmovahed Z, Dehghani $\mathrm{H}_{\text {, }}$ Zarezadeh A, Namjou Z. The effect of prayer on level of anxiety in mothers of children with cancer. Iran J Pediatr Hematol Oncol. 2012;2(2):78-83.

17. Adarvishi S, Nasiri M, Ganjou M, Asadi M. The effect of tavasol prayer on reducing test anxiety of newly registered nursing students of Ahvaz Jundishapur University of Medical Sciences. J Med Educ Dev. 2014;7(15):1-9.

18. Najafi Z, Tagharrobi Z, Taghadosi M, Sharifi K, Farrokhian A. The effect of simultaneous aromatherapy and Quran recitation on anxiety level of patients with myocardial infarction. Complement Med J Facul Nurs Midwifery. 2014;4(1):700-12.

19. Annunziata MA, Muzzatti B, Altoe G. Defining hospital anxiety and depression scale (HADS) structure by confirmatory factor analysis: a contribution to validation for oncological settings. Ann Oncol. 2011;22(10):2330-3. doi: 10.1093/annonc/mdq750. [PubMed: 21339383].

20. Kalhornia Golkar M, Banijamali S, Bahrami H, Hatami H, Ahadi H. Effect of spiritual therapy on blood pressure, anxiety and quality of life in patients with high blood pressure. $J$ Kermanshah Univ Med Sci. 2014;18(8):462-70. doi: 10.22110/jkums.v18i8.1993.

21. Montazeri A, Vahdaninia M, Ebrahimi M, Jarvandi S. The hospital anxiety and depression scale (HADS): translation and validation study of the Iranian version. Health Qual Life Outcomes. 2003;1:14. doi: 10.1186/1477-7525-1-14. [PubMed: 12816545].

22. Ap Siôn T, Francis LJ. The psychology of prayer: a review of empirical research. Int Handbook Educ Spiritual Care Well. 2009;3:247-67. doi: 10.1007/978-1-4020-9018-9_14.

23. Goolipour T, Shakerinia I, Salehi I. The effectiveness of prayer in reducing stress and anxiety. [Master Thesis]. Rasht: University of Guilan; 2014.

24. Mirbagher Ajorpaz N, Aghajani M, Shahshahani MS. The effects of music and Holy Quran on patient's anxiety and vital signs before abdominal surgery. Evid Based Care. 2011;1(1):63-76. doi: 10.22038/EBCJ.2011.3765.

25. Majidi SA. Recitation effect of Holy Quran on anxiety of patients before undergoing coronary artery angiography. J Guilan Univ Med Sci. 2004;13(49):61-7.

26. Tayyebi V, Asaadi R, Saket M, Adelnasab M, Reza-zadeh J, Kaviani A. The effect of listening to Holy Quran prayers on anxiety and vital signs before elective surgeries. Teb $\mathrm{Va}$ Tazkiyeh. 2014;23(3):45-54.

27. Pappano AJ, Wier WG. Cardiovascular physiology-e-book. NewYork: Elsevier Health Sciences; 2018. P. 269.

28. Golafshani A, Gharooni M, Faghih S, Esmaeili H. Effect of progressive muscle relaxation on hypertension of aged with myocardial infarction. Iran J Ageing. 2007;2(3):352-7.

29. Allameh T, JabalAmeli M, Lorestani K, Akbari M. The efficacy of quran sound on anxiety and pain of patients under cesarean section with regional anesthesia: a randomized case-controlled clinical trial. J Isfahan Med Sch. 2013;31(235):601-10.

30. Ildar AE, Saleh MA, Mazloom SR. The effect of Holy Quran recitation on the patient's vital signs before open heart surgery. J Sabzevar Univ Med Sci. 2003;10(1):52-8. 